\title{
Development of the System of Standardization of Quality Control of Fire Protection at Facilities
}

\author{
Sergey Bulaga ${ }^{1}$, Nikolai Smirnov ${ }^{1}$, Vladimir Bulgakov', Ol'ga Zuban', Andrei Ustinov², \\ and Ol'ga Zybina ${ }^{2,3}$ \\ ${ }^{1}$ Academy of the State Fire Service of Emercom of Russia, 129366, Boris Galushkin st, 4, Moscow, \\ Russia \\ ${ }^{2}$ Peter the Great St. Petersburg Polytechnic University, 195521 Polytechnicheskaya, 29, Saint- \\ Petersburg, Russia \\ ${ }^{3}$ FSBEE HE «Saint-Petersburg University of State Fire Service of EMERCOM of Russia», 196105, \\ Moskovsky prospect, 149, Saint-Petersburg, Russia
}

\begin{abstract}
The analysis of the existing regulatory documents in the field of quality control of fire-resistant treatment of various products and structures is carried out. The history of the development of the system of rationing the quality of fire protection is described. Information about the new standard for quality control of fire protection is provided. An example of application of methods of quality control of fire-retardant treatment is presented: the algorithm of quality control of two intumescent coatings, one taken from the existing facility, and one chosen as a control sample (the certified intumescent paint) has been practically executed. As a result, it was established that the existing quality control methods, including methods of thermal analysis, can provide adequate results and should be used ubiquitously.
\end{abstract}

\section{Introduction}

At present, the complex of issues of quality control of the fire retardant works carried out at various construction sites is quite acute, since in some cases the executing organizations do not exclude options for saving money on the fire retardant materials used, provided that in appearance, ordinary paint coatings are very similar to fire retardant thin-layer coatings $[1,2]$.

In addition, the manufacturer, as a rule, indicates the service life of a fire retardant coating at his own discretion, without having a serious technical justification for this. The situation with the real fire protection of structures and products in many cases raises doubts, especially in those cases when fire protection objects were processed more than 5 years ago $[3,4]$. In practice, the determination of the type of material used and the quality of the fire retardant work carried out is not yet widely used, since it is not a very simple and mastered procedure [5-7]. All this leads to the need of developing and improving the system for assessing control of the state of fire protection at facilities.

* Corresponding author: au.spbpu@gmail.com 
General questions of the methodology and methods of documentary and visual control at one time were set out in Russian document NPB 232-96 [8]. In addition, this document notes the need for appropriate control during the operation of fire-protected facilities, namely, to the procedure (organization) of monitoring compliance with the requirements of regulatory and technical documentation (RTD) for fire protection means. At the same time, the goal is the same - the production, use and operation of fire protection equipment must comply with the requirements of RTD.

The Guidelines for Fire Protection of Wood No. 2 describes a method for visual assessment of the quality of fire-retardant treatment of structures and wood products with compositions that form a coating layer on the surface (varnishes, paints, pastes, coatings, etc.). For a qualitative assessment of the effectiveness of fire retardant treatment of such structures with the use of impregnating fire retardants, this Guide proposes an assessment method using a small portable device.

In 2004, the Guidelines for the fire protection of textile materials « $3 »$ were published, including some issues of quality control of their fire protection.

In 2011, the FGBU VNIIPO EMERCOM of Russia developed the Guidelines «Assessment of the quality of fire protection and the establishment of the type of fire retardant coatings at facilities» [9], which sets out a generalized comprehensive approach to the problem of quality control of fire protection works, including different levels of complexity and objectivity of the assessment.

The first stage implements an evaluative approach using control according to the submitted documentation, visual control, measurement of the thickness of the fire retardant layer and control using express methods.

The second one is more accurate and informative using the methods listed above, the final stage of which is the comparative experimental identification tests of the samples of fire retardant coatings selected at the facility. These tests are carried out in laboratory conditions using thermal analysis methods - TA [9].

In 2019, Russian SP (set of rules) No. 433.1325800.2019 «Fire protection of steel structures» was published. Rules for the production of works [10] (Approved by the Order of the Ministry of Construction and Housing and Communal Services of the Russian Federation No. 38 / pr dated January 24, 2019 and entered into force on July 25, 2019).

Section 6.3 «Acceptance of fire protection works» is devoted to the assessment of the quality of the performed fire protection works.

The section also corresponds to the Guidelines [9]. As in [11], the definition of adhesion is added.

On the instructions of the Russian Emergencies Ministry in 2020, GOST R «Means for fire protection of buildings and structures. Fire protection means. Methods of quality control of fire protection works during installation (application), maintenance and repair» (final version approved by TC 465 «Construction» and TC 274 «Fire safety»).

The main section of this standard is «Methods of quality control of fire retardant works during installation (application), maintenance and repair».

The first control method is control according to the submitted documentation. This section provides information and requirements for the documentation required for quality control.

The second method is visual inspection. The section establishes requirements for visual inspection.

The next section is devoted to measuring the thickness of the fire retardant coating. It sets out the requirements for the accuracy of thickness measuring instruments depending on the thickness of the coating. The average value of the thickness of the fire retardant coating must comply with the requirements of the technical documentation for the fire protection means 
and the fire protection project (or the project for the production of works). The average value of the thickness of the fire retardant coating must be at least the design one.

The section «Methods of quality control of fire protection works for various types of fire protection object» includes: a method of quality control of fire protection work for wooden structures, quality control of fire protection work for textile materials and quality control of fire protection work on metal.

The standard also includes quality control of fire retardant works for intumescent fire retardant coatings and a method of quality control of fire retardant works using thermal analysis methods.

An important section is the procedure for applying quality control methods for fire retardant works during installation (application), maintenance and repair.

The content of these sections fully reflects the fire safety requirements necessary to fulfill the quality control of fire protection.

\section{Materials and methods}

The main methods of quality control of fire protection works carried out at the fire protection facility are:

- control over the submitted documentation;

- visual control and express control methods;

- control using measuring and experimental methods.

Express control methods include:

- a method for assessing the quality of fire protection of wood treated with impregnating compounds using a small-sized portable device;

- a method for assessing the quality of fire protection of textile materials treated with impregnating compositions, based on the signs of ignition of material samples as a result of exposure to a burner flame;

- determination of the coefficient of swelling of the coating samples.

The group of measuring and experimental methods includes methods for measuring the thickness of fire retardant coatings using various measuring instruments, as well as methods of thermal analysis (TA), which are used to identify (establish the type) of the material used and the quality of the fire retardant coating [12-14].

Express control methods characterize only a qualitative assessment of the conducted fire retardant treatment.

Evaluation of the quality of fire-retardant processing of textile materials with impregnating compounds is carried out very rarely, since it requires fabric samples of a sufficiently large size [15]. If such samples were not prepared in advance at the facility together with fire-resistant products, then it is not possible to cut them from the products in use.

The method for assessing the quality of fire-retardant wood treatment with impregnating compounds [16-18] using a small-sized portable device is based on an assessment of the flammability of wood shavings.

Methods for determining the swelling coefficient of coating samples have been used not so long ago. It is determined for any intumescent coatings, regardless of the material of the object of protection (wood, metal, cable sheaths, etc.) $[19,20]$.

To determine the swelling coefficient of coating samples, tests are carried out in accordance with the Guidelines [9].

The samples are applied on a non-combustible substrate and placed in an oven at a temperature of $600{ }^{\circ} \mathrm{C}$ and being exposed to heating for 5 minutes to obtain an expanded layer.

The swelling coefficient $\mathrm{K}$ is determined by the formula: 


$$
K=h / h_{0}
$$

where $h$ is the thickness of the expanded layer, mm;

$h_{0}$ is the initial thickness of the coating sample, $\mathrm{mm}$.

Measurements of $h$ and $h_{0}$ are carried out in sections of five samples. The swelling coefficient is defined as the arithmetic mean of five measurements. The appearance of typical samples before and after testing is shown in the figures 1 and 2.

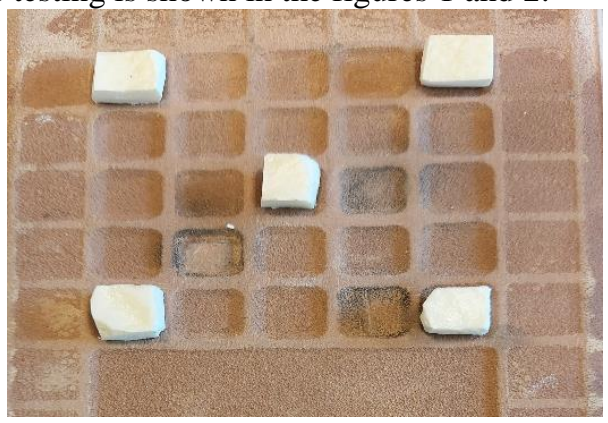

Fig. 1. Appearance of samples before testing.

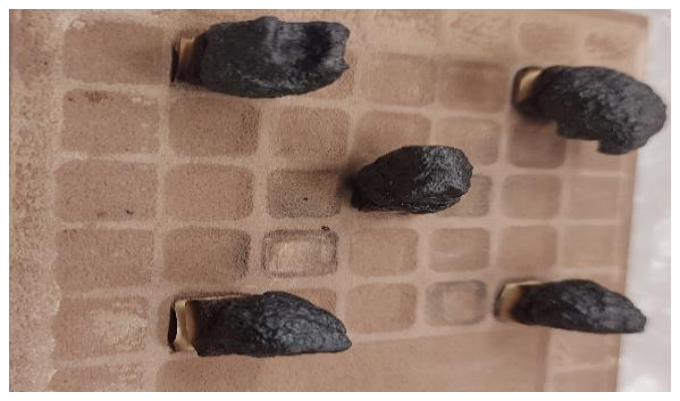

Fig. 2. Appearance of samples after testing.

From the measurement methods, one should be described in more details, and it's thermal analysis.

Evaluation of the quality of fire retardant coatings can be carried out using TA equipment on the basis of a qualitative and quantitative comparison of thermoanalytical dependences.

To carry out experimental studies using thermal analysis methods, the following types of devices were used:

- modular, in which each method is executed by one device (for example, only thermogravimetry (TG) or only differential thermal analysis (DTA);

- combined, in which separate methods (TG, DTA or differential scanning calorimetry (DSC) are executed by one device;

- with horizontal or vertical placement of reaction chambers and weighing mechanisms.

To obtain the required characteristics of the samples and the thermoanalytical characteristics of the investigated fire retardant coatings, we used an automated thermoanalytical system «Derivatograph $\mathrm{S}$ » and a multimodular device «Du Pont 2100». The derivatograph makes it possible to study materials in the form in which they are actually used in practice, and the Du Pont multimodular complex makes it possible to minimize the diffusion component of the experiment as much as possible.

Simultaneous control of the device operation, observation of the shooting progress in real time, data accumulation (TGA and DTA) in the form of experiment files, as well as processing of the results obtained, in the case of using the Derivatograph, was carried out 
using a computer equipped with specialized software for a multi-module device - using special application programs.

The instruments were calibrated against reference substances recommended for use by the International Committee for Thermal Analysis (ICTA) and a reference (verified) weight.

To obtain the identification characteristics of the samples, the automated modular thermoanalytical system «Du Pont -9900» was used (the license is established by the serial number - No. 1228). In our case, only the TGA-951 thermal balance unit was used to accomplish the task.

Thermoanalytical system (in a two-module connection option is shown in figure 3) included:

- computer (color display and system unit);

- standard interfaces connected to the system unit;

- thermal balance TGA-951;

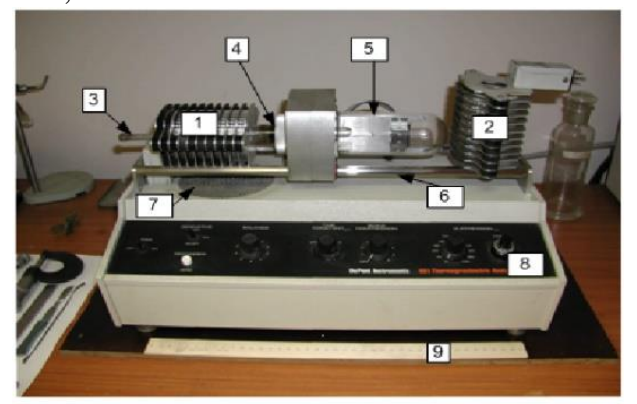

Fig. 3. Appearance of the TA device: 1 - thermal balance oven; 2 - replaceable oven; 3 - quartz tube; 4 - clamping nut; 5 - thermal balance mechanism; 6 - skids; 7 - fan; 8 - control panel; 9 - ruler $40 \mathrm{~cm}$.

\section{Results and discussion}

An example of comparing the results of thermal analysis of the coating of the fire-retardant «POZ-V» is presented below. Typical averaged thermoanalytical curves - TG, DTG and DSC are presented in figures 4-5; for clarity, fig. 6 shows the aligned curves for samples from the object and the standard.

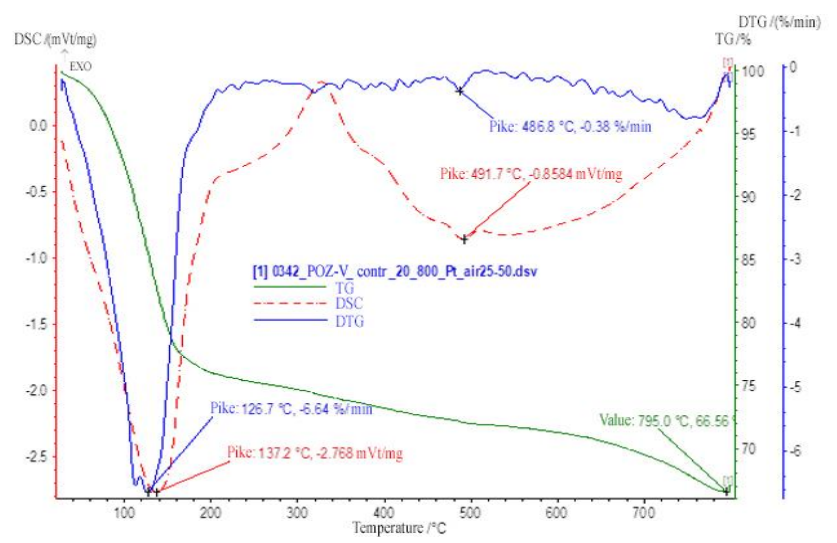

Fig. 4. Typical thermogravimetric curves of samples No. 1 and No. 2 of a fire retardant coating from metal structures of an object; 1 - TG curve (weight loss); 2 - DTG curve (rate of mass loss); 3 - DSC curve (heat transfer rate); atmosphere - air; heating rate $-20^{\circ} \mathrm{C} / \mathrm{min}$. 


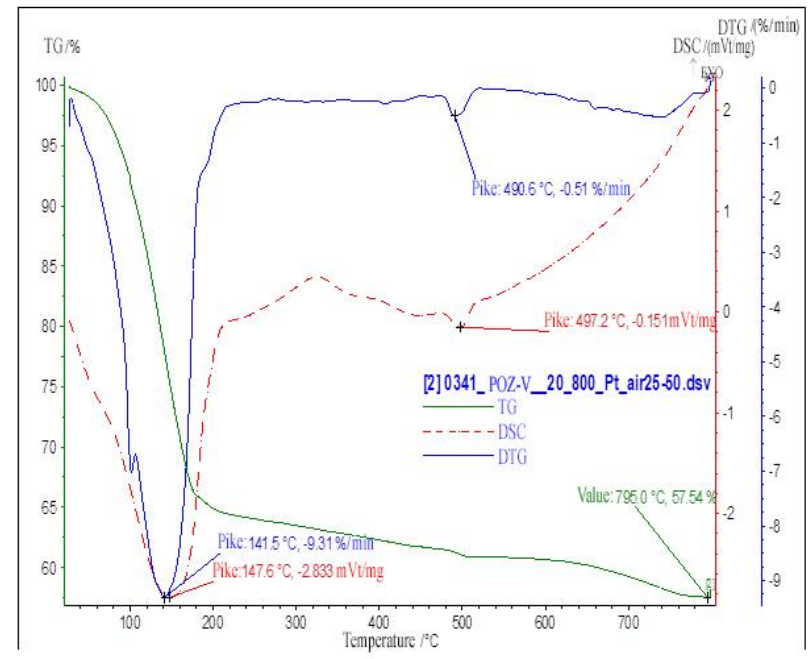

Fig. 5. Typical thermogravimetric curves of samples - the standard identifier «Fire-retardant coating «POZ-V»; 1 - TG curve (weight loss); 2 - DTG curve (rate of mass loss); 3 - DSC curve (heat transfer rate); atmosphere - air; heating rate $-20^{\circ} \mathrm{C} / \mathrm{min}$.

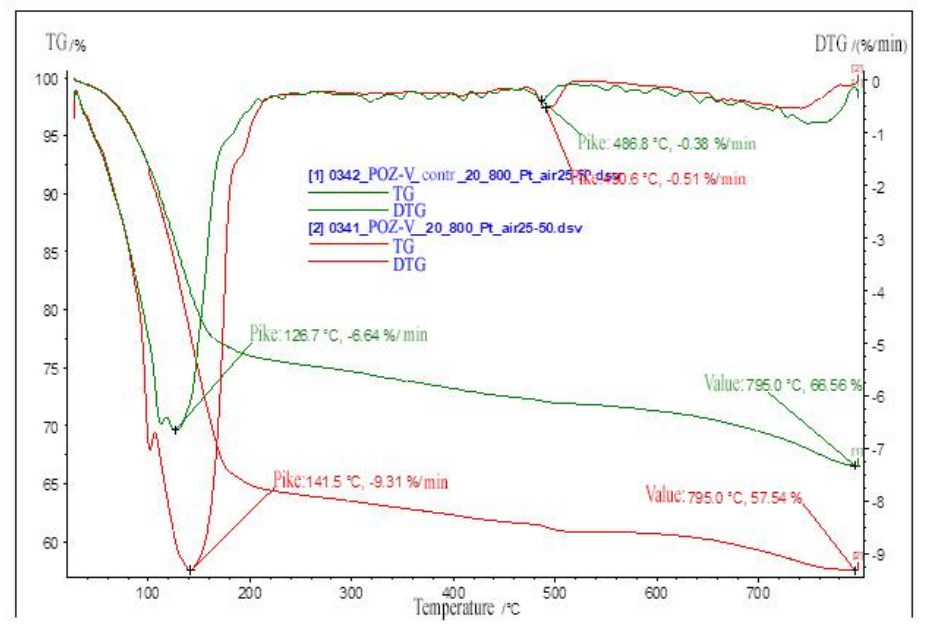

Fig. 6. Combined averaged thermoanalytical curves of samples from the object and the identifier - Fireretardant coating «POZ-V»; 1 - TG curve (weight loss); 2 - DTG curve (rate of mass loss); 3 - DSC curve (heat transfer rate); atmosphere - air; heating rate $-20^{\circ} \mathrm{C} / \mathrm{min}$.

Comparison of the results of thermal analysis according to the averaged curves of the studied samples of fire retardant coatings showed that the destruction of the samples proceeds in a similar way, regardless of the investigated coating, namely:

- at the first stage, in the temperature range from 30 to $230{ }^{\circ} \mathrm{C}$, the release of volatile components (mainly - weakly bound water) occurs, which is accompanied by heat absorption (confirmed by the presence of endothermic peaks on the DSC curve; 
- in the temperature ranges of $450-650{ }^{\circ} \mathrm{C}$ and $700-800{ }^{\circ} \mathrm{C}$, weight loss is accompanied by small endothermic effects, which corresponds to dehydration of the binder (confirmed by the presence of exothermic peaks on the DSC curve.

The analysis of identification of thermoanalytical characteristics of the samples of coatings taken from different places of the object, and the identifier - Fire-retardant coating «POZ-V» showed the following:

- the similarity of the compared thermoanalytical curves in the entire temperature range of comparison;

- coincidence of the number of significant DTG and DSC maxima.

When comparing the significant identification characteristics of the coating samples from the object and the identifier using experimentally obtained and theoretically calculated statistical criteria, no significant differences in the compositions were found. The existing differences in the intensity of weight loss in the temperature range of $30-200{ }^{\circ} \mathrm{C}$ (dehydration of the binder) are associated with the incompleteness of the curing process of the sample of the identifier coating, and, as a consequence, the increased moisture content (caused by the insufficient drying time of the coating before testing).

Thus, on the basis of the above, it can be concluded that the samples of coatings selected at the facility, according to comparative thermoanalytical tests, can be attributed to the previously certified fire retardant coating $\langle\mathrm{POZ}-\mathrm{V}\rangle$.

\section{Conclusion}

A review, analysis and generalization of the current regulatory documents on the quality control of fire retardant treatment have been carried out.

The necessity of practical application of relatively new and most informative control methods is substantiated - determination of the swelling coefficient for intumescent coatings and control using thermal analysis methods.

All methods of quality control of fire protection work during installation (application), maintenance and repair, as shown in specific examples in this article, have been successfully tested and are used by organizations that accept the fire protection work performed and monitor the state of fire protection during operation.

A brief description of GOST R «Means for fire protection of buildings and structures. Fire protection means. Methods of quality control of fire protection works during installation (application), maintenance and repair», the final version of which was approved by TC 465 «Construction» and TC 274 «Fire safety».

The use of this document in construction practice will significantly improve the quality of fire protection works and increase the fire safety of protected objects.

\section{References}

1. Lucherini, A., Maluk, C., Assessing the onset of swelling for thin intumescent coatings under a range of heating conditions, Fire Safety Journal, 2019, 106, 1-12

2. Inerhunwa, I., Chang Wang, Y., Su, M., Reliability analysis of intumescent coating protected steel members under the standard fire condition, Fire Safety Journal, 2019, 104, 43-56

3. R. Maciulaitis, M. Grigonis, J. Malaiskiene, The impact of the aging of intumescent fire protective coatings on fire resistance, Fire Safety Journal 98, 15-23 2018

4. B. Bahrani, V. Hemmati, A. Zhou, S. Quarles, Effects of natural weathering on the fire properties of intumescent fire-retardant coatings, Fire and Materials, 2018 
5. A. Martynov, V. Grekov, O. Popova, Some Reasons for the Violation of the Intumescent Coatings Quality, Occupational safety in industry, 2020, 11, 69-75

6. M. Gravit, I. Dmitriev, A. Ishkov, Quality control of fireproof coatings for reinforced concrete structures, IOP Conference Series Earth and Environmental Science, 2020, 90(1):012226

7. O. Zybina and M. Gravit, Intumescent Coatings for Fire Protection of Building Structuresand Materials, Springer Series on Polymer and Composite Materials, 2020

8. NPB 232-96 «Procedure for monitoring compliance with the requirements of regulatory documents for fire protection means (development, application and operation)», VNIIPO Ministry of Internal Affairs of Russia, 1997

9. Guidelines «Assessment of the quality of fire protection and the establishment of the type of fire protection coatings at facilities», FGBU VNIIPO EMERCOM of Russia, 2011,39 p.

10. SP 433.1325800.2019 Fire protection of steel structures. Work production rules.

11. STO NOSTROY 2.12.118-2013, Building structures of buildings and structures. Application of fire retardant coatings. Rules, control of implementation and requirements for the results of work.

12. Taylor, A.P., Sale, F.R., Thermal analysis of intumescent coatings, Eur. Polym. Paint Colours. J., 1992

13. T. Fateh, S. Benkorichi, L. Robinet, J.-L. Consalvi, Numerical Study of the Decomposition Mechanism of Intumescent Coating, Journal of Physics Conference Series 1107(3):032010, 2018

14. A. Ustinov, O. Zybina, L. Tanklevsky, V. Lebedev, A. Andreev, Intumescent coatings with improved properties for high-rise construction, E3S Web of Conferences 33, 02039, 2018

15. Konstantinova, N.I., Smirnov, N.V., Shebeko, A.Y., Tanklevsky, L.T., Flammability of polymeric materials used in construction, Magazine of Civil Engineering, 2021, 102(2), Article No. 10203. DOI: 10.34910/MCE.102.3

16. M. Hassan, R. Kozlowski, New fire-protective intumescent coatings for wood, Journal of Applied Polymer Science, 2008

17. A. Ustinov, O. Zybina, E. Kruglov, Intumescent coatings with improved properties for fireproofing of wooden building constructions, IOP Conference Series Materials Science and Engineering 986:012032, 2020

18. Y. Tsapko, O. Tsapko, O. Bondarenko, Research of the mechanism of protecting wood with intumescent coating, Technology Audit and Production Reserves 5(3(55)):19-23, 2020

19. D. de Silva, A. Bilotta, E. Nigro, Experimental investigation on steel elements protected with intumescent coating, Construction and Building Materials 205:232-244, 2019

20. V. Prusakov, M. Gravit, Y. Simonenko, A. Minnullina, Fire retardant for expansion and linear joints in buildings and tunnels, MATEC Web of Conferences 239:05010, 2018 